
constantly tried to escape in order to return to his own house. Although violent if restrained, yet, if he was not supported, he would fall after half a dozen steps from the bedside. Sleep was only obtained by the use of liberal doses of bromidia. When I saw him, he was constantly talking to the people of his father's household, whom he supposed to be about him.

ON Sept. 22d, 188 of age. He was above medium
man, fifty.two years of and height, of heavy frame and by profession a practising physician. Patient reported that he had never experienced any severe illness in his life except an attack of acute rheumatism at sixteen years of age. He never had syphilis, he had experienced several epileptiform convulsions in his life occurring at long intervals. The last one was in the spring of 1882. That he had used alcohol for many years daily, that he had used both alcohol and tobacco to excess, but that of late he had smoked less and drank more. For three months his vision had been failing until it appeared to him that he walked continually in a thick fog. Upon examination I found that his vision had fallen to 0.1 in each eye, and could not be improved by glasses. There was no astigmatism. Color vision was perfect except for a slight hesitancy on a very light green. The field of vision in each eye remained at nearly normal limits both for form and for colors. There was a distinct central color scotoma for green in each eye with a somewhat imperfect one for red. Upon an ophthalmascopic examination the nerve was seen to be congested but the fundus was otherwise normal. A diagnosis of amblyopia ex abusu was made and the patient was warned, that, unless he stopped the use of alcohol and tobacco absolutely, he stood in danger of blindness. Abstinence was advised and pil. strych. sulph. gr. 1-32 was ordered twice daily. I requested him to report to me from time to time.

I saw nothing farther of the patient until the 9th day of April, 1885, somewhat more than six months later, when $\mathrm{I}$ was called to see him in consultation with Dr. J. A. Dow; I was then told that he had abstained from alcohol and tobacco for a week after consulting me in September, and then returned to his former habits with even more devotion than before. His vision had steadily failed, until he could barely distinguish figures on the street. His walk had become peculiar and unsteady at all times. That recently, when he came in, he had complained of great fatigue and seemed quite exhausted. He sometimes on such occasions complained of rheumatic pains in his feet and legs. He had, however, continued to walk out to a friend's place of business and back, about threefourths of a mile, every day until April 1st. On that day he came home reeling from side to side and experienced great difficulty in getting up the steps to his door, indeed, he only did so by helping himself with his hands, grasping posts, etc. He was not intoxicated. Soon after his return home, he said he was perfectly blind. During the night he appeared quite ill and had delusions. He thought that he had been called to see a patient and must go out. When his family tried to restrain him, he became very violent. The next morning his vision was so poor that he could not distinguish even large objects before him. His delusions for the next four or five days were very marked. He thought that he was in the home of his childhood with

${ }^{1}$ Kead before the Cambridge Medical Improvement Society, March 22,1886 . 
right. His arms were not diminished in size and the sides. All sensitive points have disappeared from the power was but slightly diminished and that only in left arm, but he cannot completely close his left hand. the left. The left arm and hand were slightly hyper- The examination of the eyes. reveats the following asthetic accompanied by lack of sensation in the tips condition: vision equals 0.1 , certainly a remarkable of the fingers of the left hand. His pupils were only improvement. Vision for colors perfect. Fields of moderately dilated and reacted promptly to light. vision, of nearly normal size and containing no color Vision equalled fingers at $60 \mathrm{~cm}$. The intra-ocular appearance remained the same.

On May 15th, he was mentally in a much better condition and recognized me. His delusions were still prominent and he related to me on this, as often on subsequent occasions, the particulars of the cases he had attended throughout the day. He was quite helpless and unable to attend to his slightest want; he could not even feed himself. The pain upon deep pressure or voluntary movements was now marked in both arms and legs, but very much less in the right arm than in the other limbs. The pain caused by the examination was extreme. He no longer moved his left arm, always lifting it with the right hand in order to avoid the pain caused by voluntary movements. There was marked impairment of the power of the right hand. He said that his legs and left arm had a strange sensation, as if there was a fluid under the skin. In examining for anæsthetic areas on this occasion I noticed a distinct delay in the transmission of sensation.

On the 6th of June our patient continued to complain of freezing and burning sensations in the limbs at intervals. He could not stand. He had lost power over the left arm. He could only raise himself in bed by the aid of his right hand, and then only with the greatest labor. He could cross the left leg over the right only with extreme difficulty. The measurement about the calf of the left leg was twelve inches and that of the right leg twelve and one-half inches.

On June 22d, I found him much improved and his mental condition was good, except that his memory of events happening from day to day was very poor. The extreme sensitiveness of the legs had given place to a tingling sensation, which gave much discomfort. Pain could only be produced upon deep pressure. He could stand with a little assistance. The leg measurements were each one-half inch less than at the last observation. There was a marked increase of power in the right hand. He could raise the left hand as high as his head without assistance from the right. There were still several points near the axilla on the left arm, that were very painful to the touch. Voluntary movements of the left arm also caused pain. Vision 3-200, intra-ocular appearances the same.

From this time forward he continued to improve, and on the 21 st of July went down stairs, but was unable to return, as he could not lift his feet from one step to another. On that date pain on deep pressure had disappeared from both legs except from a tender point on the front of each ankle. The leg measurements had increased slightly to twelve and one-half and thirteen inches respectively.

In September our patient was able to walk up stairs for the first time. At the present date, March 18th, 1886 , he is somewhat forgetful concerning passing events. He can walk up and down stairs without effort and easily rise from a sitting posture. The measurement about the calf of the left leg at its greatest diameter is thirteen and one-half inches, and about the right is fourteen inches.

The patella tendon reflex is still absent on both

scotomata. An ophthalmoscopic examination shows marked blue-gray atrophy of both optic discs with small vessels.

During his illness he had two epileptiform attacks, such as he had previously experienced, but they did not seem to have any influence upon the progress of the disease. His treatment with the exception of bromidia given in the early stages to produce sleep at night has been simply complete abstinence, rest, and iodide of potass. given in increasing doses until fortyfive grains, three times daily, was reached. Whenever intolerance of the drug presented itself its exhibition was omitted for a week or ten days and then resumed.

This case certainly presents a group of symptoms striking in the extreme, motion, sensation, and mental condition are all affected, and in seeking for a lesion which could explain these facts, we naturally turn to the cerebro-spinal system. No brain lesion could explain them all as thus associated, and if we look to the spinal cord for the location of the lesions, which could produce at the same time the motor paralysis with atrophy of the muscles, and also abolish the patella tendon reflex, we should be obliged to suppose that there was present either acute myelitis or acute anterior poliomyelitis combined with locomotor ataxia, but many symptoms of these diseases are absent, such as the girdle sensations, the pareses of the sphincters, etc.

Moreover the particularly prominent group of subjective symptoms, namely, hyperæsthesia to touch and to passive motion, loss of tactile sensibility, sensations of heat and cold, pain on deep muscular pressure, delay in the transmission of sensations, suggests at once a multiple neuritis such as has been so well described by Leyden. ${ }^{2}$ This disease is an affection of the peripheral nerves, which does not extend to the spinal cord. When we have a multiple neuritis due to the long-continued use or abuse of alcohol, we have added cerebral symptoms, and in our case we have a typical clinical description of the condition to which of late has been given the name of alcohol paralysis. This form of the disease differs from other cases of multiple neuritis. (1) The history of the abuse of alcohol. (2) It runs a less acute course and is less progressive. (3) The paralysis is more confined to the extensor muscles. (4) The cerebral symptoms. The peculiar delusion before mentioned occurs also in chronic alcoholism without paralysis. There is a return of the patella-tendon reflex in cases of recovery but it is very late.

Within the last three years eight different observers namely, Lauceraux ${ }^{8}$ Moeli, ${ }^{4}$ Dèjèrine, ${ }^{5}$ Broadbent, ${ }^{6}$ Hun, ${ }^{7}$ Strumpel, ${ }^{8}$ Muller, ${ }^{8}$ Dreschfeld, ${ }^{9}$ have published reports of autopsies in cases of alcoholic paralysis. In every case the spinal cord was found to be normal

2 Zeitschrift für Klin. Medicin. Vol. 1, p. 387.

3 Gazette des Hopitaux, No. 46, 1883.

Berlin Klin. Wochen. No. 14, 1884

5 Archiv. de Physiologie, No. 2, 1884.

7 Royal Medical and Chir. Society, February 14, 1884.

Schultz in Neurol. Centralb., Janusry, 1886.

- Brain, January, 1886. 
and the peripheral nerves showed degenerative changes. In Dr. Hun's case the specimens of the peripheral nerves were unfortunately not preserved, but an examination of the brain revealed "a degeneration and atrophy of the nerve cells in the cerebral cortex, a congestion of the pia mater, and an effusion of serum into the sub-arachnoid space." From the above list it would appear that the pathology of the disease is well determined and consists of a degeneration of the peripheral nerve fibres and of the nerve cells of the cerebral cortex.

I have purposely omitted in the foregoing any consideration of the ocular symptoms of this case, as $I$ wish to treat the subject in some detail. Amblyopia ex abusu is an affection rarely met with before the age of thirty years. The patient comes complaining of a gradually progressive loss of sight extending over several months until it appears to him, as if he now "walked in a continual fog." He can no longer read ordinary type. He thinks he can see better after dusk or in the house. Upon examination we find that his visual acuity is reduced to from 0.1 to 0.3 of normal vision. His vision as the same in each eye. His fields of vision for form and color are of normal size, but he has an oval central color scotoma for red and green covering about $20^{\circ}$ horizontally and $10^{\circ}$ perpendicularly as measured on the arc of a perimeter. 'This scotoma includes the macula and blind spot. Upon the examination of the eye-ground with the ophthalmascope we see nothing abnormal except perhaps a slight congestion of the disc. If the patient has delayed somewhat longer before seeking advice, we shall find the discs markedly white, especially the temporal half; or if the case is one of considerable duration, the whole disc will be blue-white and present the ordinary appearance of atrophy optici. 'This loss of vision although accompanied by whiteness of the nerve, differs materially from the atrophy occurring in ataxic, cerebral, and glaucomatous disease, as well as from that of hysterical amblyopia; for in amblyopia ex abusu although the central vision is much impaired, the fields both for form and color are good; while in other forms of atrophy, on the contrary the field for form is much diminished and the color fields are greatly. contracted, or even color sense itself, especially for red and green, may be absolutely wanting before the centric vision is lost to any very considerable extent. A patient coming with these symptoms will report that he has used tobacco steadily and excessively for many years, or what is much more common, that he has used tobacco constantly but not excessively, and drank spirits daily to a considerable extent for a long time. I have repeatedly seen patients with this complaint, who drank spirits continuously, but who did not use over two ounces of tobacco per week. If such a patient can be induced to stop his tobacco and alcohol entirely, he is certain to recover his vision. The vision does not perhaps return to normal acuity, but 0.7 to 0.8 is recovered. This is the disease that is commonly called tobacco amblyopia. Much has been written to prove that tobacco, and tobacco alone, is the cause of this trouble. The English writers as a rule have followed Hutchinson, who first described the disease, attributed it to tobacco, and gave it the name generally accepted. von Græfe, Sichel, Galezowski, and others, have maintained that alcohol bore a part in the production of a majority of these cases. Hirschberg ${ }^{10}$ says that there

\footnotetext{
${ }^{10}$ British Medical Journal, November 22, 1879.
}

is a centric amblyopia, that is produced by alcohol, and quotes Brudend Carter as saying that this affection was rarely or never met with among the Turks, who notoriously smoke excessively. He does not speak of it, yet it is a fact, that the Turks as a nation, are very moderate in the use of spirits.

I have compiled all the reported cases, in which there is a record of the use of alcohol. I have not included in my list any cases, in which there is no record of the examination of the field of vision or of the existence of a central scotoma; the result is as follows:

\begin{tabular}{|c|c|c|c|c|c|}
\hline & $\begin{array}{l}\text { Number } \\
\text { of Cases. }\end{array}$ & $\begin{array}{c}\text { Used } \\
\text { Alcohol. }\end{array}$ & $\begin{array}{c}\text { Used } \\
\text { Tobacco. }\end{array}$ & $\begin{array}{c}\text { No } \\
\text { Record. }\end{array}$ & $\begin{array}{c}\text { Teetotal- } \\
\text { ers. }\end{array}$ \\
\hline $\begin{array}{l}\text { Nettleship } 11 \\
\text { Shear 12 } \\
\text { Hartridge is: } \\
\text { Morton 14 } \\
\text { Webster } 15:\end{array}$ & $\begin{array}{l}26 \\
40 \\
20 \\
1 \\
20\end{array}$ & $\begin{array}{r}26 \\
38 \\
16 \\
0 \\
19\end{array}$ & $\begin{array}{r}26 \\
.40 \\
20 \\
1 \\
20\end{array}$ & $\begin{array}{l}\mathbf{0} \\
\mathbf{0} \\
\mathbf{3} \\
\mathbf{0} \\
\mathbf{0}\end{array}$ & $\begin{array}{l}0 \\
2 \\
1 \\
1 \\
1\end{array}$ \\
\hline Totals. . . & 107 & 99 & 107 & 3 & 5 \\
\hline
\end{tabular}

From which summary it will be seen that, out of a total of one hundred and seven cases, there were only five teetotalers, ninety-nine are recorded as using alcohol to a greater or less extent, and in three cases there is no record.

Nettleship, in commenting upon his cases, says that alcohol is a predisposing cause. This, I think, may be accepted as a fact, and to this I would add that the greater the abuse of alcohol, the less the quantity of tobacco necessary to produce the toxic effect. As alcohol is at least such a powerful adjuvant in the production of this disease of the eyes, I prefer to call it amblyopia ex abusu, and it does not seem strange to find this condition co-existent with alcohol paralysis.

For the purpose of determining whether such an association may not often be the case, I have collated all the published cases of undoubted alcohol paralysis with especial reference to their eye symptoms. I find the total number of cases reported to be fourty-four, as follows :

Glynn ${ }^{16}$ four, Fischer ${ }^{17}$ two, Kruche ${ }^{18}$ seventeen, Dèjèrine $^{19}$ two, Hun ${ }^{20}$ two, Dreschfeld ${ }^{21}$ eight, Moeli ${ }^{22}$ two, and Strumpel ${ }^{28}$, Muller ${ }^{23}$, Schultz ${ }^{23}$, Lowenfeld ${ }^{24}$, Lilienfeld ${ }^{23}$, Myrtle ${ }^{25}$, Broadbent ${ }^{26}$, one each. In none of these cases is there any record of the amount of vision, either centric or peripheric, but there cannot be deduced from this a conclusion that it was not often, and even seriously, impaired, for a sick person can easily lose a very large proportion of his acuity of sight without noticing it.

In consequence of this non-examination of vision, we must depend for our evidence upon the recorded results of the ophthalmoscopic examinations and upon observed abnormalities of the pupil. The total number of cases reported is forty-four. An examination

11 St. Thomas Hospital Reports, 1878

12 British Medical Journal, June 21, 1884

${ }^{13}$ British Medical Journal, January 20, 1886.

1. Shears in British Medical Journal, June 21, 1884

15 Medical Record, 1880.

${ }_{16}$ Liverpool Med. Chir. Journal, July, 1883.

17 Archiv. Phychiatrie u. Nervenkrank. Vol. xii.

18 Deutsche Medizinal Zeitung, September 8, 1884.

10 Archiv. de Physiologie, No., 2, 1884.

20 American Journal of Medical Sciences, April, 1885

21 Brain. July, 1884, and January, 1886.

22 Charite Annalen, No. viii, 1883. Berl. Klin. Wocheuf, No. 14, 1886.

${ }_{28}^{28}$ Neurol. Centralb., No. $2,1885$.

24 Archiv. Phychiatrie u. Nervenkrank, Vol. xv.

25 British Medical Journal, August, 1882.

20 Lancet, February 16, 1884. 
of the fundus of the eye is noticed in twenty-three cases; of these, seven are recorded as having no change in the eye ground, ten as having congested discs, four as having white discs, and finally two cases, in which the temporal half of the disc was distinctly white. In all these cases there was no other intraocular abnormality recorded. All of these appearances would be explained, by the supposition that an amblyopia ex abusu existed. Moreover, the whitening of the temporal half of the disc is quite characteristic of this disease.

In addition to these cases in which there is a record of the condition of the fundus, three other cases are reported as having large pupils, which reacted slowly to light. Such a condition of the pupil is always present when the amblyopia has considerably advanced. From which it will be seen that although only fiftytwo per cent. were carefully examined with reference to their eyes, forty-three per cent. of the total number present symptoms which at least suggest the presence of a toxic amblyopia.

There is one case recorded by Shears in his report of cases of tobacco amblyopia, which is extremely interesting in this connection, and is recorded in substance as follows :

The patient had a vision in each eye of 20-200. Dises pale on temporal half. Central scotomata. $\mathrm{He}$ almost ceased smoking but continued the use of alcohol. His vision did not improve in three months, while under observation. The patient subsequently had alcoholic paraplegia. This case is certainly entirely parallel with ours, and in connection with the suggestive statistics given above, would indicate that the acuity and fields of vision should be examined in every case of alcoholic paralysis. ${ }^{27}$ It would be interesting also to know what proportion of these cases used tobacco. This association of a multiple peripheric neuritis, the pathology of which is known, with a toxic amblyopia, the pathology of which is unknown, as it never terminates fatally, is particularly interesting, and it does not seem improbable that the morbid processes may be identical. In both diseases the tendency of the disease is to recovery, if the use of the toxic agent or agents can be prohibited.

\section{EDUCATION AND CARE OF THE IDIOT.}

BY ASBURY G. SMITh, M.D.,

Superintendent of the Massachusetts School for the Feeble-Minded.

THIs paper will not aim at presenting any new feature of this work nor at exhausting any particular branch of it; idiocy, its care and treatment, has received the attention of scientific men for but little more than half a century, and when first it was noticed, it was with the greatest lack of sympathy and interest on the part of all but a very few. To-day but little is really known about it, even among the members of the medical profession, and hence the writer ventures to offer some general information.

The history of the work of educating idiots can be briefly told, for although idiots have existed from the 1 Read before the Boston Medico-Psychological Society, February
18, 1886 .

27 Since writing the above, Dr. G. L. Walton has related to me two cases of alcoholic multiple neuritis, which he had seen, and upon referring to his notes found in each case dimness of vision recorded as a symptom. earliest time, and likewise, kind-hearted and true mothers, who doubtless labored earnestly for the improvement of their defective offspring, yet of these cases we have no record, and the earliest account of any scientific attempt to ameliorate the condition of an idiotic person, is that which relates the efforts of Itard with the savage of the Aveyron, at the very beginning of the present century. Far back in the middle ages, the professional jester or court-fool had been sought from among the less defective of the feeble-minded; the hideously deformed and dwarfed had also been selected as prizes for the tyrants and rulers of that period. Fortunate were those who had a spark of wit or a grotesque deformity, by which to secure for them at least a certainty of freedom from want, while the less fortunate were a curse among the people and to themselves. They were neglected, and left to perish from want and exposure, and when houses of refuge and the like seemed to offer the much-needed shelter for the poor outcast idiot, it was sought by himself or his friends only to be found a place where cruel and abusive treatment made his life miserable, until death put an end to his existence.

It was not until after the reform in the care of the insane had begun, that idiocy received any attention, and not at all as a sequel of that reform.

The savage of the Aveyron had been found and brought to Paris as a scientific wonder; no one supposed him to be an idiot, but he became the subject of a good deal of scientific study. It was then universally admitted that the condition of idiocy could not be relieved. Once an idiot, always an idiot. Starting with a belief in this proposition, and not considering his strange pupil an idiot, Itard labored for several years to educate the savage, with results which convinced him that he had been dealing with an idiot, and that he had very much improved his condition, showing at once the prevalent belief in the improvability of idiocy to be false. This produced something of a sensation in scientific circles at the very beginning of this century, and the French Academy of Sciences made official mention of this savage, and his improvement under the care of Itard.

Notwithstanding this announcement, the matter slept for a score of years, and idiots still remained objects of the common people's hatred. The seed had been sown, however, and the history of this savage became the first recorded case of the amelioration of the condition of an idiot. Earlier scientific mention of idiots may be said to have been made by the great naturalist, Linnæus, who collected the histories of several similar cases, although he regarded them as a distinct species of the genus homo, and did not recognize what we now know to have been idiocy.

About the year 1827, observations were made on some idiots at the Bicêtre, who were noticed to improve intellectually while in the Hospital, and some zealous French physicians and psychologists set about the work of teaching these persons. In 1835, a school for idiots was established in Paris, the first in the world, and a few years later, more were organized in other countries. About the same time, in 1842, observations were made in America, in the Blind Asylum in South Boston, by Dr. S. G. Howe, upon some feeble-minded children admitted to that institution unintentionally, and he became convinced of the plausibility of educating idiots in America, and at once became an enthusiast in the work. Further experiments and observations 